\title{
Predicting the Risk of Insolvency in Small Enterprises: Critical Analysis of the Predictive Model Associated with the New Italian Code of Business Crisis
}

\author{
Anna Maria Arcari ${ }^{1} \&$ Daniele Grechi ${ }^{2}$ \\ ${ }^{1}$ DiECO, University of Insubria, Varese, Italy \\ 2 DiSUIT, University of Insubria, Como, Italy \\ Correspondence: Anna Maria Arcari, Department of Economics (DiECO), University of Insubria, Via Monte \\ Generoso, 71, Varese, VA, Italy. E-mail: anna.arcari@uninsubria.it
}

Received: April 28, 2021

doi:10.5539/ijbm.v16n7p41
Accepted: May 20, 2021

Online Published: June 8, 2021

\begin{abstract}
Numerous studies have been conducted to verify whether, and under what conditions, Altman's Z-Score model can also be applied to unlisted, non-US companies. The response of numerous studies confirms the substantial validity of this algorithm. However, in Italy, the legislator, in launching the new Business Crisis Code in 2019, in adherence to an important European recommendation, did not adopt the aforementioned model but approved a different one. In order to find a justification for this choice, the present work intends to test the effectiveness of the warning indices that will be adopted in Italy by comparing them with the Altman predictive model in the Z" Score version. To this end, the two models were applied to the balance sheets of 789 Italian firms that went bankrupt in the period 2016-2018 and, at the same time, to a control sample, equal in number and composition, of non-bankrupt firms.

The results of this analysis produced two distinct findings. The Italian method proved to be less effective in predicting a crisis than the Z" score. but more effective in determining whether a firm is truly healthy. This evidence is useful to confirm once again the effectiveness of the Z" Score in a non-American context but also, and above all, to provide suggestions to the Italian legislator so that it can refine the predictive model currently in force.
\end{abstract}

Keywords: Alert indices, bankruptcy code, code of business crisis, crisis predictive models, crisis management, small companies

\section{Introduction}

The last twelve years have seen an unprecedented turnover of businesses in Italy. The 2008 financial crisis has inevitably affected the balance of the real economy, on the one hand fueling virtuous circles, which have given a new impetus to entrepreneurship, especially among young people, and on the other, vicious circles, which have led to the disappearance of many companies. If that were not enough, the coronavirus pandemic, which has affected the entire globe since the early months of 2020, and the proactive and reactive restrictive measures that all governments have been forced to take to contain the contagion will produce deleterious effects on the world economic system that will not be short in duration. SMEs have been the absolute protagonists of these dynamics, and unfortunately, we imagine that they will also be in the scenario over the next few years. In fact, their small size is an element of vulnerability, not only because of the scarcity of resources that these companies can put in place to overcome a crisis situation but also because SMEs are subject to growth and degrowth rates and, more generally, to rates of change that are much more sustained than those typical of large companies, making "precariousness" a constant in every phase of their life cycle and exposing them to high risks of failure. There is no clear and unambiguous definition of "failure" in the literature, and different terms are used to identify this event (Ropega, 2011): the exit or death of the organization (Swaminathan, 1996), organizational collapse (Argenti, 1976), bankruptcy or default (Altman,1968; Laitinen, 1991), decline (Chowdhury \& Lang 1993), etc. What all these definitions have in common is the recognition that "failure" is identified with the final act of an enterprise and, consequently, with its exit from the market. This event produces damage not only to property but also to the entire eco-system of relationships and interests that had been created during the life of the company. 
This explains the usefulness of deploying a series of tools, not only on a management level but also on a regulatory level, aimed at predicting and preventing bankruptcy. In the Italian legal system, failure is a liquidation procedure aimed at "satisfying creditors through the liquidation of the entrepreneur's assets", which can be used if certain requirements are met. Bankruptcy is therefore the declaration of the death of the undertaking. Every entrepreneur is responsible for ensuring the continuity of his or her business and avoiding its undesired liquidation, a situation that can generate heavy social costs beyond the loss of the entrepreneur's assets. From this perspective, following the recommendation of 2014/135/EU on a new approach to business failure and insolvency, the Italian legislature has revised the bankruptcy law, now the "Code of Business Crisis", by issuing Decree Law No. 14 of 12 January 2019. This is a regulatory system that has succeeded in restoring systematicity and organicity to the relative legal system and replacing its bases, which are ineffective and still vaguely punitive towards the entrepreneur (Danovi \& Acciaro 2019a; 2019b). The introduction of the new code has represented a real revolution, in that great attention is paid to the tools and procedures that the legislature makes available to businesses to diagnose, address and exit from precarious economic and financial situations. This whole new reform is evidently based on the recognition that the ability to intervene promptly at the first ominous signs and not only at the manifestation of an open crisis is the real objective to be pursued.

In the light of this premise, the present research aims to evaluate the effectiveness of the crisis warning tools explained in the aforementioned decree. From a methodological point of view, via hypothesis testing and logistic regression, the present work tries to compare and analyze the two methods in order to understand their effectiveness). Therefore, it will be compared with tools that have long been recognised by management theory and practice as suitable for predicting the risk of default, in particular Altman's Z" Score. The results of our analysis have highlighted some limitations of the protocol developed by the CNDCEC (National Council of Chartered Accountants and Accounting Experts) that suggest a critical reconsideration of the choices currently implemented (Vella, 2019).

\section{The Relevance of the Topic in the Literature}

In the field of management studies, at the beginning of the 1930s and starting with the first contribution of Fitz Patrick (1932) on company failure, a specific field of research emerged, which found an outlet in different veins (Brooks, 1964; Deeson, 1972; Ross \& Kami 1973; Arendt, 1977; Altman, 1983; Crutzen \& Van Caillie, 2008, Niresh \& Prathepaan, 2015). In the light of these studies, the real challenge is to develop an alert system capable of anticipating the unwanted outcome of the processes of decline. Therefore, it is within this horizon that the importance of our research, to which we have gone further in the analysis of the literature in a way that is strictly functional with respect to the definition of the boundaries and contents of our study, is inscribed. The most interesting contributions can be traced back to three strands of studies: classical thought, transition theory and the strand of predictive models of corporate crises. Classical thought (Burns \& Stalker, 1961) argues that a crisis is an "extraordinary and undesirable" event but, at the same time, "inevitable" for any company and, in extreme cases, "useful" to the system as it generates a natural selection of companies (Chisholm-Burns, 2010). Alongside this extreme perspective, other studies that graft onto classical thought, focus on the "progressiveness" of a crisis (Gao \& Alas, 2010; Habermas, 1973; Cazdyn, 2007; Heath, 1998; Sloma, 2000) and the "difficulty" of stopping the degenerative process (Slatter, Lovett \& Barlow, 2008). The second perspective, which we call transitional (Peters \& Waterman, 1982; Normann \& Ramirez, 1995), argues that crises occur not because they are inevitable but because companies are unable to discern alarm signals and, therefore, are unable to predict and prevent them. The authors of this school insist on the concept that every company must learn to recognize the risk of a crisis and prepare to take more or less radical change actions to avoid the disastrous effects of irreversible decline (Slatter, et al., 2008). Closely linked to the previous line of research is the business failure prediction literature, studies aimed at designing useful models for predicting company crises. The traditional and most widespread models are those developed in the 1960s and 1970s. They are still preferred because they are characterised using mathematical and statistical methodologies that are not particularly complex and require inexpensive and unsophisticated technical and IT instruments. The methodologies that fall into this group (Balcaen \& Ooghe, 2004) are those based on multiple discriminant analysis (MDA) models, among which different versions of Altman's Z-Score stand out, i.e., those calibrated based on logit models (generally used by banks to analyse the risk of their client portfolios) and Bayesian techniques (Anderson, 1958) that combine and synthesize typically quantitative variables (financial predictors) to estimate the probability that a company will default. The seminal works in the MDA field are those of Beaver and Altman, who developed univariate (Beaver, 1966) and multivariate (Altman, 1968) analysis models, respectively, using a series of financial indices to predict company failures (Note 1) (Altman, Hartzell \& Peck 1995; Altman, Hotchkiss, 2006; Altman \& Sabato, 2007). Altman developed his first Z-Score model in 1968 and, over time, either individually or with other scholars, he has 
revised this original version to adapt it to contexts other than those for which it was built, i.e., American, manufacturing and listed companies. In 1993, the first adaptation for unlisted companies was called the Z' Score. In 1995 , the Z" Score was developed to consider the sector to which a company belongs; therefore, it is also applicable to non-manufacturing companies and non-American contexts. The latter model was applied during a survey conducted in 2013 on a sample of Italian firms undergoing extraordinary administration procedures in the period 2000-2010 (Altman, Danovi \& Falini 2013; Altman, Sabato \& Wilson, 2010; Altman, Sabato \& Esentato, 2010; Altman, 2017). The study led to some very important empirical evidence that allows us to conclude that Altman's Z" Score is definitely one of the best models for predicting corporate crises (Bottani, Cipriani \& Serao, 2004). Similar confirmations come from studies (Qiu, Rudkin \& Dlotko, 2020; Muñoz-Izquierdo, Laitinen, Camacho-Miñano \& Pascual-Ezama, 2020) conducted in very different country contexts (Shafitra, Rizka \& Norman, 2020; Milašinović; Knežević \& Mitrović, 2019) and referring to companies belonging to different types of sectors (Bimpong, et al., 2020), different corporate forms, un listed and listed company (Guanglu, 2021). A less recent but significant study for us (Celli, 2015) was conducted in 2015 in Italy on a sample of 102 industrial companies listed in the period 1995-2013, of which 51 went bankrupt and 51 not bankrupt. This and the other studies confirm that Altman's model also works effectively in other countries including Italy, although sometimes with a slightly lower degree of reliability than the American experience. We therefore wondered why the bodies entrusted by the legislator with the task of developing a protocol for predicting the state of crisis did not make use of this more than proven and validated model. One of the reasons perhaps lies in the fact that while the model's validations have been made in medium-large companies, the 2019 bankruptcy reform particularly affects small companies.

\subsection{Purpose of the Study}

The aforementioned literature has therefore led us to consider the comparison of the two methods of analysis and for this motivation in this section we present and we analyze critically the CNDCEC and Z-Score methods, to have a clear framework of the two models, summarizing their strengths and weaknesses.

\section{Methodological Specificities of the Predictive Models Used: Similarities and Differences}

In order to make the reader understand the specificities of the Italian method, taking Altman's Zeta Score as known, here is a brief description of the protocol developed by the CNDCEC in implementation of the new Code of Business Crisis. The CNDCEC method is based on a sequential approach. It starts with the evaluation of Equity, which, if it is negative or below legal requirements, is a sufficient condition to declare a crisis situation. If it is positive, the DSCR (Debt Service Coverage Ratio) is considered, which assesses the ability of cash flows to meet the company's financial needs over the next six months. Only if this ratio is below 1, or not available, are five balance sheet ratios considered. The latter have been chosen by the CNDCEC following the indications of art. 13 of the new Code of Business Crisis. According to the legislator, in fact, the indices to be adopted to conduct the investigation must be able to "measure the sustainability of debt burdens with the cash flows that the company is able to generate, and the adequacy of its own means compared to those of third parties. Significant and repeated payment delays are also indicators of crisis". The new Code has also entrusted the CNDCEC with the task of drawing up, every three years, specific sectoral indices to which to refer in order to diagnose an actual state of crisis.

Since the purpose of our work is to assess the signalling ability of the indices developed by the CNDCEC, the comparison with the signalling effectiveness of the Altman index is justified for reasons of methodological affinity. The two models share the same statistical similarities (multivariate discriminant techniques) and check all the fundamental areas for the health of a company (liquidity, profitability, debt and the ability of a company to repay its debts) with apparently marginal methodological differences:

- The CNDCEC model consists of a "hierarchical system of indices" that does not result in a multivariate scoring of indices as in Altman's model, but provides temporary evidence of a combination of events exceeding thresholds (distinct by sector) whose joint emergence is historically associated with a high probability of default (see CNDCEC 2019 report).

- The CNDCEC model offers more items to serve the model, some of which are not considered by the Z" Score, such as financial expenses, cash flow or social security and tax liabilities, but the Z" Score also uses items not considered by the CNDCEC model, such as net income and working capital. These differences will be further detailed in the next section and taken up in the discussion of the results to assess whether, and to what extent, they may affect the possible different predictive ability of the two models.

\subsection{CNDCEC Methodology}


As we have said the CNDCEC approach provides three steps to determine and, consequently, verify the dichotomous result if a company is in a state of crisis or if a company is healthy.

The first level of evaluation is applied by determining the book equity of the company under analysis. If the result is negative or below the legal limit for corporations (50,000 euro for S.P.A. and S.A.P.A., 10,000 euro for S.R.L.), the company in question will be considered to be in a state of crisis. In the event that the result is positive or for a value above the legal limit mentioned above, we will move on to the second level of analysis.

The second level of analysis involves calculating the six-month DSCR (Debt Service Coverage Ratio), which is the result of the ratio between the free cash flows expected in the following six months that are available for the repayment of debts expected over the same period. If this ratio is less than 1, the company is considered to be in crisis. In the opposite case, a third level analysis is carried out.

The third level of analysis involves the calculation of 5 indices, for each of which the CNDCEC has indicated separate alert thresholds by sector (see the CNDCEC document). They are:

- The sustainability index of financial charges;

- The equity adequacy ratio;

- The cash flow return ratio of assets;

- The liquidity ratio;

- The index of social security and tax indebtedness.

If the calculation of these ratios, considered together and not separately, were to exceed all the alert thresholds for the various sectors, then and only then would the company be judged to be in a state of "crisis" and induced to follow the procedures set out in the new code. If, on the other hand, even one of these indices is below the alert threshold, the company would not be considered to be in "crisis".

\subsection{Altman's Z" Score Model}

Alman's Z" Score model (1995 and subsequent adaptations 2000 and 2005), which uses linear regression as its statistical analytical methodology, is the result of a long series of studies and improvements to the initial model. All of Altman's models, from the 1968 model to the most recent models, lead to the calculation of a score (Z) whose value will have to be compared with some predefined thresholds to assess the presence of a critical situation.

Alman's Z" Score, which we have chosen to use, uses the following formula to calculate the score (Z"):

$$
Z^{\prime \prime}=6.56 X_{1}+3.26 X_{2}+6.72 X_{3}+1.05 X_{4}+3.25 X_{5}
$$

The (Z"), based on weighting coefficients calculated by the author on a sample of companies composed of an equal number of failed and healthy companies, represents a value that, if compared with some predefined ranges, allows us to place the analysed company in three different zones: the safe zone, which attests to the good health of the company; the distress zone, which denotes a condition of instability or crisis; and the grey zone, which delimits an area of uncertainty. The reference intervals, known as the score value (Z"), are shown in the following table.

Table 1. The "zone" that certifies the health of an enterprise

\begin{tabular}{cc}
\hline$Z^{\prime \prime}>6.25$ & Safe zone \\
\hline$Z^{\prime \prime}<4.75 \mathrm{C}$ & Distress zone \\
$4.75<\mathrm{Z}^{\prime \prime}>2.60$ & Grey zone \\
\hline
\end{tabular}

In fact, it should be stressed that the "score" does not have a probabilistic value that is useful for quantifying the degree of risk to which the company is exposed. Much more simply, the score is a descriptive and comparative value for assessing whether an enterprise belongs to one cluster or another. Regarding the calculation methodology and the meaning of the variables within the model, the following applies. The first variable, X1, is the ratio between net working capital (which we calculate through the corresponding item in AIDA database (Note 2) and for consistency with the previous model) and total assets. The weighting coefficient linked to the variable is 6.56. The second variable, $\mathrm{X} 2$, is net income compared to total assets. The weighting factor linked to the variable is 3.26 . The third variable, $\mathrm{X} 3$, is operating income as a proportion of total assets. The weighting 
coefficient linked to the variable is 6.72 . The fourth variable, $\mathrm{X} 4$, consists of the ratio between book shareholder equity (which is calculated by excluding from item $\mathrm{A}$ on the liabilities side of the balance sheet - shareholder equity - the item 'amounts due from shareholders for payments still due' - and item A on the assets side of the balance sheet - any resolved dividends not yet accounted for and the item "reserve for operations to cover expected cash flows" to comply with the calculation methods of the CNDCEC model) and total company payables (calculated as the sum of item D - payables - and item E - accruals and deferrals - of the balance sheet liabilities). The weighting coefficient linked to the variable is 1,05 . The last value, +3.25 , is a constant. It serves to standardize the results equal to 0 , i.e., those that should indicate companies in default.

\subsection{Research Question}

Since the two models share the same statistical similarities (multivariate discriminant techniques) and check all the fundamental areas for the health of a company (liquidity, profitability, debt and the ability of a company to repay its debts), the hypothesis we wish to test is whether the two models are indeed able to express the same predictive capacity and, if not, which of the two is more effective and for what reasons. To summarize, the two models differ in the representation, numerosity and composition of the variables considered (Table 2).

Table 2. Structure and articulation of the two methodologies: elements of similarity and diversity

\begin{tabular}{|c|c|c|c|c|c|c|c|c|}
\hline $\begin{array}{l}\text { INCOME } \\
\text { VARIABLES }\end{array}$ & CDNCEC & $\begin{array}{l}" \\
\text { SCORE }\end{array}$ & $\begin{array}{l}\text { DEBT } \\
\text { VARIABLES }\end{array}$ & CDNCEC & $\begin{array}{l}Z^{\prime \prime} \\
\text { SCORE }\end{array}$ & $\begin{array}{l}\text { FINANCIAL } \\
\text { VARIABLES }\end{array}$ & CDNCEC & $\begin{array}{l}" \\
\text { SCORE } \\
\end{array}$ \\
\hline Financial Charges & YES & NO & Book Net Equity & YES & YES & Cash Flow & YES & NO \\
\hline Revenues & YES & NO & $\begin{array}{l}\text { Total } \\
\text { Debts }\end{array}$ & YES & YES & & & \\
\hline Net Income & NO & YES & $\begin{array}{l}\text { Total } \\
\text { Assets }\end{array}$ & YES & YES & & & \\
\hline \multirow[t]{4}{*}{$\begin{array}{l}\text { Operational } \\
\text { Income }\end{array}$} & $\mathrm{NO}$ & YES & Short-Term Assets & YES & NO & & & \\
\hline & & & $\begin{array}{l}\text { Short-Term } \\
\text { Liabilities }\end{array}$ & YES & NO & & & \\
\hline & & & $\begin{array}{ll}\text { Social Security } \\
\text { Payables }\end{array}$ & YES & NO & & & \\
\hline & & & $\begin{array}{ll}\text { Net } & \text { Working } \\
\text { Capital } & \\
\end{array}$ & & YES & & & \\
\hline
\end{tabular}

First, the CNDCEC model does not make use of a multivariate index score, which characterizes Altman's model. More simply, it shows a combination of exceedance events whose joint emergence is associated with a high probability of default. Secondly, the variables covered by the two models vary in number and articulation: the model proposed by the CNDCEC, in addition to using one more "index" than the Z" Score, considers up to 9 different variables or macro-items for their calculation (financial charges, turnover, accounting net worth, total debts, total assets, short-term assets and liabilities, social security debts and cash flow), while the Z" Score uses only 6 (net result, operating result, accounting net worth, total debts, total assets, net working capital).Third, regarding the balance sheet profile and the value of assets and liabilities, the two models are substantially aligned (including, for the balance sheet profile, the value of book equity, total payables and total assets; for the composition of short-term sources and uses, or separate items of short-term assets and liabilities in the CNDCEC protocol, or the value of net working capital in the Z" Score). However, one difference lies in the tax item, which is covered only by the CNDCEC model (cf. Article 15 of the Business Crisis Code). At the income level, the differences are more evident. First, the CNDCEC model focuses its attention on the value of turnover, providing for threshold levels of alert indices differentiated by sector, while the Z" score makes no distinction whatsoever (the prerogative of the Z" Score compared to other Altman indices is to include weightings that make it suitable for different sectors). Moreover, the CNDCEC model expressly includes the amount of financial charges, which are considered only indirectly by the Z" Score through the value of the operating result and the net result. Finally, the CNDCEC model reinforces its focus on the financial aspects of management, considering the cash flow calculation. This last observation makes it possible to isolate a further element of diversity that is not irrelevant between the two models.

Summarizing, the literature and the analysis of the two models leads us to formulate the following research question: considering the proposed models (Z" Score and CNDCEC) and their composition, which of these 
models is more capable of predicting the economic and financial problems of a sample composed by small and medium size enterprises?

\section{Methodology}

The final objective of this research is to test the effectiveness of the model proposed by the CNDCEC in predicting the state of crisis of a company, evaluated in relation to the results obtained by applying Altman's Z" Score. The research will be carried out on a composite sample of companies: a group of companies in "crisis" and a group of "healthy" companies, the latter with control functions to verify any signal errors of the two models (companies wrongly detected as being in crisis). The observation of the indices and/or scores calculated for the three-year period 2016-2018, together with the bankruptcy (and procedural) dynamics occurring in the time interval considered, will make it possible to express not only a generic evaluation of the "predictive ability" of the two models but also their "timeliness" in terms of signalling. The latter will be related to the time distance that will be recorded between the year in which the alert signal is generated (time of diagnosis) and the year in which the crisis becomes manifest, including the possibility of a forecasting error (verified with the sample of healthy companies for the same period). To verify our hypothesis, three different techniques are applied. First, the technique of descriptive statistics is used to describe the basic characteristics of the data collected in an experiment. Secondly, we used hypothesis testing techniques (Note 3). In this specific case, the work will compare the means of two samples where the variance of the population is not known. For this motivation, the instrument used is the Two-sample t-tests for a difference in mean involve independent samples. Finally, to verify the influence of the Z-Score coefficients, logistic regression is used. It is a nonlinear regression model used when the dependent variable is dichotomous. The objective of the model is to establish the probability with which an observation can generate one or the other value of the dependent variable; it can also be used to classify observations into two categories based on their characteristics (for further information see: Martire, 2013).

\subsection{Sample Selection}

The sample selection was made with different selection steps, in the first phase of the analysis was aimed at understanding which sectors should be analyzed due to their data availability and potential sample size. In Table 3 , it is possible to find the selected ATECO codes to have a picture of the following analysis. Company selection followed two criteria: for companies with financial problems, we selected the following ATECO (Note 4) codes as represented in Table 3. The decision to use the following ATECO codes is due to the availability of data. In fact, we have found in a preliminary analysis other companies related to some different ATECO codes but their numerosity (both for the sample and for the control group) were not sufficient to carry out an accurate analysis. Finally, for the control sample, the random sampling method was used (see Knüsel, 2005; Mélard, 2014 for information related to this method). It is important to precise that the control sample is made by companies of the same ATECO sector that have not any economic or financial problem in the considered period.

Table 3. The selected ATECO codes - population and sample

\begin{tabular}{|c|c|c|c|c|c|}
\hline ATECO & Description & $\begin{array}{l}\text { Total number of } \\
\text { firms }\end{array}$ & $\begin{array}{l}\text { Sample with } \\
\text { characteristics }\end{array}$ & boundary & $\begin{array}{l}\text { Sample } \\
\text { Size }\end{array}$ \\
\hline 10 & Food industries & 15526 & 1106 & & 38 \\
\hline 13 & Textile industries & 5678 & 653 & & 34 \\
\hline 14 & Manufacture of clothing & 9719 & 537 & & 44 \\
\hline 15 & Manufacture of leather and similar articles & 6883 & 597 & & 36 \\
\hline 22 & Manufacture of rubber and plastic products & 7305 & 1091 & & 31 \\
\hline 23 & Manufacture of other non-metallic mineral products & 7958 & 706 & & 34 \\
\hline 25 & $\begin{array}{l}\text { Manufacture of metal products (excluding machinery and } \\
\text { equipment) }\end{array}$ & 36350 & 3616 & & 93 \\
\hline 28 & Manufacture of machinery and equipment & 17185 & 2528 & & 54 \\
\hline 41 & Building construction & 88941 & 1131 & & 50 \\
\hline 43 & Specialized building construction & 61810 & 1692 & & 75 \\
\hline 45 & Retail trade and repair of motor vehicles and motorcycles & 33543 & 915 & & 37 \\
\hline 46 & General trade (except of motor vehicles and motorcycles) & 123806 & 4712 & & 182 \\
\hline 49 & Land transport and pipeline transport & 27439 & 1111 & & 45 \\
\hline \multirow[t]{2}{*}{68} & Real estate activities & 78618 & 266 & & 36 \\
\hline & Total & 520761 & 16987 & & 789 \\
\hline
\end{tabular}


The model made available by the CNDCEC, as previously analysed, is primarily aimed to small and medium-sized enterprises. This influenced the criteria used for oud sample definition, applying a structured filter over a dimensional range and using the provisions of the decree of the Ministry of Productive Activities of April $18,2005$.

For this reason, the boundary characteristics that defined the sample are the following (that are representative of small companies):

- Turnover of between 2 million euro and 10 million euro;

- Total assets of between 2 million euro and 10 million euro;

- A number of employees between 10 and 50.

It is important to precise that it was decided to not include medium-sized and microenterprises in the selection. The first category was excluded first due to numerical reasons (only some companies), while the latter companies were excluded because their financial statements contain excessively aggregated data that could affect our quantitative analyses.

Subsequently we have defined the sample to identify companies that were without active procedures in 2015 (Note 5) but subject to bankruptcy or procedures in the following three years. In fact, we have selected companies that had bankrupt or other procedures (insolvency, debt restructuring agreement, compulsory administrative liquidation) between 2016 and 2018. The reason for this sample choice involves the aim of the reform: being able to predict crisis or financial distress through the application of the available instrument to activate immediately a recovery phase using the different procedures made accessible by the new code.

The final result of our sample selection was a sample of 789 companies subject to bankruptcy proceedings (or other financial procedures) in the period 2016 - 2018. The 2 models will therefore be applied to this sample of companies, which will also be joined by a set of companies (with the same number, 789) with the same ATECO codes that did not have procedures in the same period. This control sample will also be useful for verifying the type I errors in the application of the models to have an implementation with statistical relevance.

\section{Results}

Table 4 describes the sample considered, divided by ATECO codes. The number of balances analyzed differs between ATECO because the number of companies with problems (and the consequent control sample) is not the same for each sector. Another element to discuss and explain is the number of valid financial statements; in fact, it is possible that, due to the bankruptcy or due to some problems in the in the AIDA database, not all data were available.

In the next table, considering columns 3 to 5 , we find the percentage of companies that, according to the two methodologies used, exceeded the threshold values. The results are related to the entire sample, considering 4 years (as an average value).

As the percentage increases, there are a greater number of companies that are considered with financial problems. We have decided to analyse also the second step of the CNDCEC method to obtain a wide picture of our sample even if, as reported in the theoretical section of the paper, it is not a necessary step if the first step does not detect an alarm signal. 
Table 4. Z Score and CNDCEC comparison

\begin{tabular}{|c|c|c|c|c|c|}
\hline ATECO & $\begin{array}{l}\text { No. } \\
\text { of } \\
\text { firms }\end{array}$ & $\begin{array}{c}\text { Available } \\
\text { Balance } \\
\left(\max n^{\circ * 4)}\right.\end{array}$ & $\begin{array}{c}\text { Percentage of Companies } \\
\text { with Financial Problems } \\
\text { Z Score }\end{array}$ & $\begin{array}{c}\text { Percentage of Companies } \\
\text { with Financial Problems } \\
\text { CNDCEC I }\end{array}$ & $\begin{array}{c}\text { Percentage of Companies } \\
\text { with Financial Problems } \\
\text { CNDCEC II }\end{array}$ \\
\hline 10 & & & & & \\
\hline $\begin{array}{c}\text { Distressed } \\
10\end{array}$ & 38 & 135 & $64.44 \%$ & $24.44 \%$ & $1.48 \%$ \\
\hline $\begin{array}{c}\text { Healthy } \\
13\end{array}$ & 38 & 152 & $22.37 \%$ & $2.94 \%$ & $0.00 \%$ \\
\hline $\begin{array}{c}\text { Distressed } \\
13\end{array}$ & 34 & 124 & $58.06 \%$ & $22.58 \%$ & $2.42 \%$ \\
\hline $\begin{array}{c}\text { Healthy } \\
14\end{array}$ & 34 & 136 & $13.24 \%$ & $0.00 \%$ & $0.00 \%$ \\
\hline $\begin{array}{c}\text { Distressed } \\
14\end{array}$ & 44 & 138 & $57.97 \%$ & $29.71 \%$ & $3.62 \%$ \\
\hline $\begin{array}{c}\text { Healthy } \\
15\end{array}$ & 44 & 176 & $14.20 \%$ & $0.00 \%$ & $0.00 \%$ \\
\hline $\begin{array}{c}\text { Distressed } \\
15\end{array}$ & 36 & 126 & $53.17 \%$ & $11.90 \%$ & $1.59 \%$ \\
\hline $\begin{array}{c}\text { Healthy } \\
22\end{array}$ & 36 & 139 & $15.83 \%$ & $0.00 \%$ & $0.00 \%$ \\
\hline $\begin{array}{c}\text { Distressed } \\
22\end{array}$ & 31 & 108 & $48.15 \%$ & $21.30 \%$ & $0.93 \%$ \\
\hline $\begin{array}{c}\text { Healthy } \\
23\end{array}$ & 31 & 123 & $31.71 \%$ & $0.00 \%$ & $0.00 \%$ \\
\hline $\begin{array}{c}\text { Distressed } \\
23\end{array}$ & 34 & 120 & $60.00 \%$ & $23.33 \%$ & $2.50 \%$ \\
\hline $\begin{array}{l}\text { Healthy } \\
25\end{array}$ & 34 & 134 & $32.09 \%$ & $0.75 \%$ & $0.00 \%$ \\
\hline $\begin{array}{c}\text { Distressed } \\
25\end{array}$ & 93 & 320 & $66.25 \%$ & $24.38 \%$ & $1.88 \%$ \\
\hline $\begin{array}{c}\text { Healthy } \\
28\end{array}$ & 93 & 371 & $21.29 \%$ & $0.27 \%$ & $0.00 \%$ \\
\hline $\begin{array}{c}\text { Distressed } \\
28\end{array}$ & 54 & 194 & $56.19 \%$ & $31.44 \%$ & $1.03 \%$ \\
\hline $\begin{array}{c}\text { Healthy } \\
41\end{array}$ & 54 & 215 & $26.51 \%$ & $0.00 \%$ & $0.00 \%$ \\
\hline $\begin{array}{c}\text { Distressed } \\
41\end{array}$ & 50 & 160 & $54.38 \%$ & $26.88 \%$ & $2.50 \%$ \\
\hline $\begin{array}{c}\text { Healthy } \\
43\end{array}$ & 50 & 199 & $34.17 \%$ & $0.50 \%$ & $0.00 \%$ \\
\hline $\begin{array}{c}\text { Distressed } \\
43\end{array}$ & 75 & 262 & $50.76 \%$ & $18.70 \%$ & $16.41 \%$ \\
\hline $\begin{array}{l}\text { Healthy } \\
45\end{array}$ & 75 & 219 & $24.66 \%$ & $0.00 \%$ & $3.20 \%$ \\
\hline $\begin{array}{c}\text { Distressed } \\
45\end{array}$ & 37 & 131 & $72.52 \%$ & $25.19 \%$ & $21.37 \%$ \\
\hline $\begin{array}{c}\text { Healthy } \\
46\end{array}$ & 37 & 147 & $39.46 \%$ & $0.00 \%$ & $0.00 \%$ \\
\hline $\begin{array}{c}\text { Distressed } \\
46\end{array}$ & 182 & 630 & $60.79 \%$ & $25.40 \%$ & $1.11 \%$ \\
\hline $\begin{array}{c}\text { Healthy } \\
49\end{array}$ & 182 & 725 & $25.66 \%$ & $0.83 \%$ & $0.28 \%$ \\
\hline $\begin{array}{c}\text { Distressed } \\
49\end{array}$ & 45 & 137 & $57.66 \%$ & $21.90 \%$ & $11.68 \%$ \\
\hline $\begin{array}{c}\text { Healthy } \\
68\end{array}$ & 45 & 178 & $44.38 \%$ & $0.00 \%$ & $0.00 \%$ \\
\hline $\begin{array}{c}\text { Distressed } \\
68\end{array}$ & 36 & 127 & $77.95 \%$ & $44.88 \%$ & $5.51 \%$ \\
\hline Healthy & 36 & 144 & $29.86 \%$ & $0.00 \%$ & $0.00 \%$ \\
\hline
\end{tabular}

Regarding the different ATECO codes in our sample, on table 4 it is possible to verify that the two methodologies differ completely in their results.

Considering companies with financial problems, the Z" Score criterion systematically and correctly detects for each ATECO code a higher percentage of problematic companies than the CNDCEC criterion. The highest value 
recorded is in ATECO sector 68, which highlights how this method is able to correctly identify $77.95 \%$ of firms with financial problems.

For each ATECO code, the CNDCEC criterion (first step) is able to detect correctly several problematic companies, but the percentage is systematically lower than the results of the Z" Score. In this regard, the last column shows that the second level (when the calculation is necessary) detects only a small portion of the companies in difficulty.

On the other hand, in regard to the control sample composed of healthy companies, there are the opposite results since the Z" score criterion detects a percentage of companies with problems (which in reality do not exist since these companies did not report any insolvency or bankruptcy procedure) constantly higher than that detected by the CNDCEC criterion. For companies without financial problems, the latter criterion has only 5 ATECO codes (with a maximum value of $2.94 \%$ ) where there is an alarm signal related to companies that have no financial problems.

From a descriptive point of view, there is a clear difference between the results of the two methodologies. In fact, companies with financial problems are identified precisely by the Z" Score criterion (which, however, has some false positives in the control sample), while the CNDCEC method detects almost $100 \%$ of healthy businesses. Importantly, however, the CNDCEC model has a low capability to identify companies in difficulty considering both the first and second steps.

Table 5 shows the entire set of hypothesis testing phases, divided by ATECO and methodology (Z" Score or CNDCEC) with the value of the hypothesis testing and the level of significance. As anticipated in the methodological section, the objective of this analysis is to identify whether the values of the Z" Score and the CNDCEC differ in a statistically significant way considering the average of the values that emerged for healthy companies and companies with financial/bankruptcy problems". Consequently, a hypothesis test of the difference between the averages considering the Z" Score values and a hypothesis test for the difference between the averages considering the CNDCEC values (step II) are provided. For statistically significant tests, there is a significant difference between the scores obtained by companies without financial problems vs companies with financial/bankruptcy problems.

Table 5. Hypothesis Testing - Z SCORE and CNDCEC

\begin{tabular}{|c|c|c|c|c|}
\hline \multirow{2}{*}{ ATECO } & \multicolumn{4}{|c|}{ Test and P-Value (Level of significance) } \\
\hline & 2018 & 2017 & 2016 & 2015 \\
\hline 10 ZSCORE & $-4.192(* * *)$ & $-3.389(* * *)$ & $-3.605(* * *)$ & $-3.699(* * *)$ \\
\hline 10 CNDCEC & $3.038(* * *)$ & 1.179 & 0.065 & -0.244 \\
\hline $13 \mathrm{ZSCORE}$ & $-3.044(* * *)$ & $-2.617(* *)$ & $-3.327(* * *)$ & $-3.029(* * *)$ \\
\hline 13 CNDCEC & 0.838 & 0.64 & 1.427 & -0.46 \\
\hline $14 \mathrm{ZSCORE}$ & $-2.983(* * *)$ & $-3.82(* * *)$ & $-3.488(* * *)$ & $-2.745(* *)$ \\
\hline 14 CNDCEC & $2.327(* *)$ & 0.969 & 0.481 & 1.455 \\
\hline $15 \mathrm{ZSCORE}$ & $-3.253(* * *)$ & $-3.209(* * *)$ & $-1.712(*)$ & -0.669 \\
\hline 15 CNDCEC & $3.973(* * *)$ & $2.422(* *)$ & 0.414 & 0.663 \\
\hline $22 \mathrm{ZSCORE}$ & -0.993 & -1.845 & -1.224 & $-1.695(*)$ \\
\hline 22 CNDCEC & -0.714 & -1.058 & 0.055 & 0 \\
\hline $23 \mathrm{ZSCORE}$ & $-3.827(* * *)$ & $-3.053(* * *)$ & $-3.07(* * *)$ & $-2.357(* *)$ \\
\hline 23 CNDCEC & 0.235 & -0.982 & 0.175 & -1.517 \\
\hline $25 \mathrm{ZSCORE}$ & $-2.051(* *)$ & $-5.552(* * *)$ & $-4.576(* * *)$ & $-5.832(* * *)$ \\
\hline 25 CNDCEC & $2.686(* *)$ & 0.319 & -0.478 & -1.641 \\
\hline $28 \mathrm{ZSCORE}$ & $-2.541(* *)$ & $-3.254(* * *)$ & $-3.499(* * *)$ & $-2.422(* *)$ \\
\hline 28 CNDCEC & $2.928(* * *)$ & $2.488(* *)$ & $2.323(* *)$ & 0.156 \\
\hline $41 \mathrm{ZSCORE}$ & $-3.301(* * *)$ & $-1.91\left(^{*}\right)$ & $-1.746(*)$ & $-2.078(* *)$ \\
\hline 41 CNDCEC & $2.55(* *)$ & 1.382 & 0.918 & 0.502 \\
\hline $43 \mathrm{ZSCORE}$ & $-3.487(* * *)$ & $-3.374(* * *)$ & $-3.288(* * *)$ & $-2.748(* * *)$ \\
\hline 43 CNDCEC & $1.736\left(^{*}\right)$ & 1.628 & 1.624 & 0.175 \\
\hline $45 \mathrm{ZSCORE}$ & -1.232 & -1.594 & $-3.26(* * *)$ & $-3.262(* * *)$ \\
\hline 45 CNDCEC & $3.733(* * *)$ & $4.315(* * *)$ & $3.225(* * *)$ & $2.876(* * *)$ \\
\hline 46 ZSCORE & $-5.581(* * *)$ & $-5.711(* * *)$ & $-6.447(* * *)$ & $-2.814(* * *)$ \\
\hline 46 CNDCEC & $2.226(* *)$ & 0.238 & 1.314 & -0.184 \\
\hline $49 \mathrm{ZSCORE}$ & $-1.9(*)$ & -1.15 & -1.456 & -0.904 \\
\hline 49 CNDCEC & 0.304 & 0.656 & 0.033 & -0.642 \\
\hline $68 \mathrm{ZSCORE}$ & $-2.913(* * *)$ & -2.512 & $-3.502(* * *)$ & $-3.353(* * *)$ \\
\hline 68 CNDCEC & $1.87(*)$ & $2.279(* *)$ & 1.64 & 0.219 \\
\hline
\end{tabular}

Note. Signif. codes: $0.001^{\text {‘***’ }} 0.01^{\text {‘**’ }} 0.05^{\text {‘*’ }} 0.1$. 
Considering the results, there is a clear discrepancy between the two methodologies. The test on the Z" Score values better highlights the difference between healthy and problematic companies. In fact, in 48 out of 56 tests, there is a statistically significant difference between the two groups. The critical issues of the $\mathrm{Z}$ Score are highlighted in sectors 22, 45 and 49, where these differences are not clearly highlighted with this sample. Most likely, in these sectors, the financial statements are not very different between the two groups. It may seem that the values derived from healthy enterprises and enterprises with financial problems are similar (and, therefore, are not statistically significant). Otherwise, considering sectors $10,13,14,25,43$ and 46 , the p-value (for the four considered years) is less than 0.01 , highlighting a strong difference between the two groups. The same test, based on the CNDCEC criterion (step II), provides less statistically relevant results; in fact, only in 16 out of 56 cases is it possible to show that some statistically significant differences emerge between the two samples of companies. Considering ATECO codes 45 and 28, there is a better significance with the CNDCEC data compared to the tests performed on the Z" Score data.

Considering these results, it is possible to underline that the significance decreases when older data are used, which is quite logical since at time n-1, n-2, etc., companies could have a better financial situation.

\subsection{Predictive Abilities of the Two Models: An Analysis}

As previously explained, the aim of this work is to verify the capacity to predict a future crisis using the Z" Score methodology and the CNDCEC method. The importance of this instrument, already underlined in the theoretical section, could be fundamental for understanding whether the signals of firm crisis are highlighted in advance, for the entire ATECO samples analysed, to be considered as a reliable method that can be applied for the small and medium size enterprises.

The following tables (6 and 7) show, representing using percentage, the sample of companies with economic and/or financial problem and their potential alert signal according to the Z" Score and CNDCEC indices. A predictive method should be able to grasp these aspects some time before the real manifestation. Consequently, values between -3 and -1 (i.e. from 3 to 1 year earlier) would be a useful indication because, in this way, a company could take appropriate economic and financial measures to avoid other problems, up to the point of bankruptcy.

Table 6 shows the percentage of companies that have had an alert signal in a period of more or less 3 years from the effective occurrence (through the implementation of a bankruptcy or debt restructuring procedure) of the same using the Z" Score.

Table 6. Time to Alert with the Z" Score

\begin{tabular}{ccccccccc}
\hline \multirow{2}{*}{ ATECO } & \multicolumn{7}{c}{ Time to Alert: Z" Score } \\
\cline { 2 - 9 } & $\mathbf{- 3}$ & $\mathbf{- 2}$ & $\mathbf{- 1}$ & $\mathbf{0}$ & $\mathbf{1}$ & $\mathbf{2}$ & $\mathbf{3}$ & No info \\
\hline 10 & $38.46 \%$ & $2.56 \%$ & $7.69 \%$ & $15.38 \%$ & $0.00 \%$ & $0.00 \%$ & $2.56 \%$ & $33.33 \%$ \\
13 & $34.29 \%$ & $8.57 \%$ & $8.57 \%$ & $11.43 \%$ & $2.86 \%$ & $0.00 \%$ & $2.86 \%$ & $31.43 \%$ \\
14 & $33.33 \%$ & $17.78 \%$ & $13.33 \%$ & $6.67 \%$ & $0.00 \%$ & $0.00 \%$ & $0.00 \%$ & $28.89 \%$ \\
15 & $32.43 \%$ & $5.41 \%$ & $13.51 \%$ & $13.51 \%$ & $0.00 \%$ & $0.00 \%$ & $0.00 \%$ & $35.14 \%$ \\
22 & $15.63 \%$ & $15.63 \%$ & $0.00 \%$ & $18.75 \%$ & $3.13 \%$ & $0.00 \%$ & $0.00 \%$ & $46.88 \%$ \\
23 & $27.78 \%$ & $8.33 \%$ & $22.22 \%$ & $5.56 \%$ & $0.00 \%$ & $0.00 \%$ & $0.00 \%$ & $36.11 \%$ \\
25 & $34.88 \%$ & $15.12 \%$ & $15.12 \%$ & $10.47 \%$ & $3.49 \%$ & $0.00 \%$ & $2.33 \%$ & $18.60 \%$ \\
28 & $21.82 \%$ & $12.73 \%$ & $12.73 \%$ & $14.55 \%$ & $3.64 \%$ & $0.00 \%$ & $1.82 \%$ & $32.73 \%$ \\
41 & $32.00 \%$ & $12.00 \%$ & $10.00 \%$ & $14.00 \%$ & $0.00 \%$ & $0.00 \%$ & $0.00 \%$ & $32.00 \%$ \\
43 & $23.08 \%$ & $15.38 \%$ & $12.31 \%$ & $7.69 \%$ & $1.54 \%$ & $0.00 \%$ & $0.00 \%$ & $40.00 \%$ \\
45 & $42.11 \%$ & $7.89 \%$ & $10.53 \%$ & $13.16 \%$ & $0.00 \%$ & $0.00 \%$ & $0.00 \%$ & $26.32 \%$ \\
46 & $34.07 \%$ & $11.54 \%$ & $7.14 \%$ & $15.38 \%$ & $0.55 \%$ & $1.10 \%$ & $0.55 \%$ & $29.67 \%$ \\
49 & $31.82 \%$ & $20.45 \%$ & $6.82 \%$ & $6.82 \%$ & $2.27 \%$ & $2.27 \%$ & $0.00 \%$ & $29.55 \%$ \\
68 & $40.00 \%$ & $17.14 \%$ & $11.43 \%$ & $8.57 \%$ & $2.86 \%$ & $0.00 \%$ & $0.00 \%$ & $20.00 \%$ \\
Mean & $31.55 \%$ & $12.18 \%$ & $10.81 \%$ & $11.57 \%$ & $1.45 \%$ & $0.24 \%$ & $0.72 \%$ & $31.47 \%$ \\
\hline
\end{tabular}

From the table, it is possible to underline that compared to the effective crisis period (time 0), the Z" Score is able to detect approximately $50 \%$ of the cases from 3 periods to 1 period before. Notably, regarding the percentages, there is a certain homogeneity among the majority of ATECO codes. In fact, the highest percentage value tends to be at the -3 period; therefore, these companies had already encountered financial problems 3 
periods before, such as having signals within the Z" Score. It should be noted that approximately $30 \%$ of the sample is not considered in this analysis for two main reasons: first, the Z Score was not able to recognize the crisis $(20 \%$ of the sample) and, second, there was a lack of information $(11 \%)$. The same procedure is replicated with the CNDCEC method and the results are summarized below in Table 7. Due to the limited number of problems signalled by the CNDCEC method, a table is provided by sector and with the difference between the crisis and the provisional method, but as emerged previously, the results confirm the inability of this method to be a good proxy for this situation.

Table 7. Time to Alert with CNDCEC

\begin{tabular}{|c|c|c|c|c|c|c|c|c|}
\hline \multirow{2}{*}{ ATECO } & \multicolumn{8}{|c|}{ Time to Alert: CNDCEC } \\
\hline & -3 & -2 & -1 & $\mathbf{0}$ & 1 & 2 & 3 & No info \\
\hline 10 & $0.00 \%$ & $0.00 \%$ & $0.00 \%$ & $6.06 \%$ & $0.00 \%$ & $0.00 \%$ & $0.00 \%$ & $93.94 \%$ \\
\hline 13 & $0.00 \%$ & $0.00 \%$ & $2.90 \%$ & $2.90 \%$ & $0.00 \%$ & $0.00 \%$ & $0.00 \%$ & $94.20 \%$ \\
\hline 14 & $0.00 \%$ & $4.55 \%$ & $2.27 \%$ & $2.27 \%$ & $0.00 \%$ & $2.27 \%$ & $0.00 \%$ & $88.64 \%$ \\
\hline 15 & $0.00 \%$ & $0.00 \%$ & $0.00 \%$ & $5.71 \%$ & $0.00 \%$ & $0.00 \%$ & $0.00 \%$ & $94.29 \%$ \\
\hline 22 & $3.23 \%$ & $0.00 \%$ & $0.00 \%$ & $0.00 \%$ & $0.00 \%$ & $0.00 \%$ & $0.00 \%$ & $96.77 \%$ \\
\hline 23 & $3.13 \%$ & $0.00 \%$ & $0.00 \%$ & $0.00 \%$ & $0.00 \%$ & $0.00 \%$ & $0.00 \%$ & $96.88 \%$ \\
\hline 25 & $3.19 \%$ & $0.00 \%$ & $0.00 \%$ & $2.13 \%$ & $0.00 \%$ & $0.00 \%$ & $0.00 \%$ & $94.68 \%$ \\
\hline 28 & $0.00 \%$ & $0.00 \%$ & $1.85 \%$ & $0.00 \%$ & $0.00 \%$ & $1.85 \%$ & $0.00 \%$ & $96.30 \%$ \\
\hline 41 & $0.00 \%$ & $1.96 \%$ & $0.00 \%$ & $3.92 \%$ & $0.00 \%$ & $0.00 \%$ & $0.00 \%$ & $94.12 \%$ \\
\hline 43 & $3.08 \%$ & $7.69 \%$ & $9.23 \%$ & $4.62 \%$ & $0.00 \%$ & $0.00 \%$ & $0.00 \%$ & $75.38 \%$ \\
\hline 45 & $0.00 \%$ & $10.81 \%$ & $8.11 \%$ & $8.11 \%$ & $0.00 \%$ & $0.00 \%$ & $0.00 \%$ & $72.97 \%$ \\
\hline 46 & $0.00 \%$ & $0.00 \%$ & $0.00 \%$ & $1.10 \%$ & $0.00 \%$ & $0.00 \%$ & $0.00 \%$ & $98.90 \%$ \\
\hline 49 & $4.55 \%$ & $4.55 \%$ & $2.27 \%$ & $2.27 \%$ & $0.00 \%$ & $0.00 \%$ & $0.00 \%$ & $86.36 \%$ \\
\hline 68 & $0.00 \%$ & $8.57 \%$ & $0.00 \%$ & $2.86 \%$ & $2.86 \%$ & $0.00 \%$ & $0.00 \%$ & $85.71 \%$ \\
\hline Mean & $1.23 \%$ & $2.72 \%$ & $1.90 \%$ & $3.00 \%$ & $0.20 \%$ & $0.29 \%$ & $0.00 \%$ & $90.65 \%$ \\
\hline
\end{tabular}

The results are completely different; in fact, $90.65 \%$ ( $8 \%$ of this percentage is in this field, but it is related to missing data) of the sample is not considered because this method does not signal the crisis if there is only one of the 5 indicators above the safety threshold. In conclusion, considering this information, it is possible to affirm that the importance of the Z" Score to understand the current business situation and also to have a wide picture of the financial evolution of the firms, while the CNDCEC methodology proves to be totally ineffective from a forecasting point of view.

\subsection{Regression Model on the Z" Score Coefficient}

The last analysis is related to checking what was previously observed. Using R-Studio a logistic regression model is applied to the sample of companies with financial/structural problems, using the set of characteristics analysed in the previous section as independent variables and the dummy variable that explains whether a firm is or is not in crisis as the dependent variables.

The model is composed of four independent variables, which are the indices defined by the Z" Score model. The sample is composed by year (with a time frame of 4 years, from 2015 to 2018), using the entire datasets of the previous analysis, without an ATECO distinction and, for this reason, this step is different, as it uses grouped data. It was decided to carry out this overall analysis due to the differences in the number of companies considering one single ATECO code sample. In fact, for some sectors, due to the small number of firms, this analysis would not have been statistically congruent and significant. It was not possible to implement a panel data analysis due to a sample reduction caused by the data quality. In fact, as already mentioned, it is possible that the financial statements of the companies are not always available for the 4 years considered as some of them have gone bankrupt in the meantime.

The following four models are provided and represent the same time frame used for the previous analyses Table 8 . 
Table 8. Logistic regression models

\begin{tabular}{|c|c|c|c|c|c|c|}
\hline \multirow{2}{*}{ Variable } & \multicolumn{3}{|l|}{2015} & \multicolumn{3}{|l|}{2016} \\
\hline & Estimate & Z_Value & Significance & Estimate & Z_Value & Significance \\
\hline Intercept & 0.36 & 5.18 & $* * *$ & 0.49 & 6.57 & $* * *$ \\
\hline (Current Assets - Current Liabilities)/Total assets & -0.1 & -2.67 & $* *$ & -0.15 & -4.7 & $* * *$ \\
\hline Retained earnings/total assets & -0.01 & -0.062 & & 0.75 & 1.61 & \\
\hline Earnings before interest and taxes/total assets & -1.27 & -8.27 & $* * *$ & -1.92 & -8.623 & $* * *$ \\
\hline Book value of equity/total liabilities & 0.04 & 1.03 & & 0.12 & 1.03 & \\
\hline AIC & 1943 & & & 1806 & & \\
\hline \multirow{2}{*}{ Variable } & 2017 & & & 2018 & & \\
\hline & Estimate & Z_Value & Significance & Estimate & Z_Value & Significance \\
\hline Intercept & 0.58 & 7.11 & $* * *$ & 0.53 & 7.21 & $* * *$ \\
\hline (Current Assets - Current Liabilities)/Total assets & -0.22 & -7.07 & $* * *$ & -0.13 & -12.76 & $* * *$ \\
\hline Retained earnings/total assets & 4.01 & 2.08 & $*$ & 5.01 & 2.06 & * \\
\hline Earnings before interest and taxes/total assets & -2.89 & -7.42 & $* * *$ & -3.37 & -10.74 & $* * *$ \\
\hline Book value of equity/total liabilities & 0.15 & 2.04 & $*$ & 0.05 & 2.05 & * \\
\hline AIC & 1777 & & & 1726 & & \\
\hline
\end{tabular}

As shown on the previous Table, variable 1, corresponding to the ratio between net working capital and total assets, and variable 3 , corresponding to the ratio between operating profit and total assets, can all be considered significant. Therefore, they guarantee that the model has good predictive ability. They have the same negative significance for all 4 years, thus indicating that lower values of these variables negatively affect the economic and financial situation of companies. The second (retained earnings/total assets) and the fourth (book value of equity/total liabilities) variables are not significant for the first 2 years, but they are weakly significant and positive for 2017 and 2018. It is possible to state that the dynamics of these two variables are in any case elements to be kept under observation because they seem to influence the overall problems of companies considered to be in a business crisis, even if only slightly.

\section{Discussion and conclusions}

\subsection{Discussion}

The results of our analysis reveal two distinct realities linked to the methods used. The Z" Score method is very effective in identifying companies at risk of failure Its ability to verify this problem reaches a peak of $77 \%$, and it is systematically more efficient than the CNDCEC method. The CNDCEC method has the peculiarity of being able to establish with certainty whether a company is healthy: it can reveal that a company has no financial problems with effectiveness reaching a peak of nearly $100 \%$. Unfortunately, this method does not have the same detection ability as the Z" Score in companies at risk of default; in fact, for a large portion of the analysed data, its predictive average percentage is much lower than that of the Z" Score. In the second step of analysis, referring to the difference between the calculated values between healthy and problematic companies, this divergence between the two methods further emerges. The differences between the average values by sector from the Z" Score coefficients are relevant for some sectors. Consequently, with this method, it is possible to affirm that the calculation and its final result statistically significantly differ between good companies and bad companies. Finally, focusing attention on the difference in coefficients based on the CNDCEC method (II step) once again shows the slightly better ability to identify healthy companies compared to bad companies. Based on a hypothesis testing technique, the coefficients regarding the two groups are similar. This means that in most cases, the second step of the CNDCEC method has similar values between healthy companies and companies with known financial/legal problems. Regarding predictive capability, the comparison between the two models is clearly skewed in favour of the Z" Score. In fact, this method can provide good predictive ability for firms that can be helped by this instrument to understand their economic situation. In contrast, the CNDCEC method is shown to have very poor predictive abilities. This is certainly due to the mechanism through which this method defines a company in crisis. Finally, in the analysis of the regression model on the Z" Score, the Z" Score is able to help companies (from an overall point of view) understand the most relevant components of these methods that can influence the situation of crisis. 


\subsection{Conclusions}

The field of study in which we can place this research is that of the previously mentioned transition theory. It considers the 'crisis' as a phenomenon inherent in the growth processes of businesses but, at the same time, predictable and avoidable in its extreme manifestation, in some cases capable of generating opportunities for change which are not always perceived in normal conditions. The same perspective motivated our legislator in the process of revising the legislation on corporate bankruptcy and insolvency, leading him to draft the new 'Corporate Crisis Code'. The CNDCEC, in agreement with the legislator, has taken care to construct the algorithm to be used to foresee crisis situations to which to refer a "rescue" protocol.

Specifically, our research confirmed a number of interesting propositions found in the literature including:

- The progressiveness of the crisis (Gao \& Alas, 2010; Habermas, 1973; Cazdyn, 2007; Heath, 1998; Sloma, 2000),

- The difficulty of recognizing the degenerative process (Slatter et al., 2008) and discerning the alarm signals (Peters \& Waterman 1982; Normann \& Ramirez 1995);

- The need to intervene promptly at the first signs of decline to avoid irreversible situations (Slatter et al., 2008);

- The need to use effective crisis forecasting models, including univariate (Beaver, 1966) and multivariate (Altman, 1968) analysis models.

In this regard the contribution of our research consists in having demonstrated that two models compared, Altman's Z" Score, whose effectiveness is widely demonstrated, and the CNDCEC model, which were initially considered equivalent due to methodological similarities, have in fact a different signalling capacity. The predictive model that has proved to be more functional for the purpose is without a shadow of a doubt Altman's Z" Score.

At the basis of default there is often a liquidity crisis, especially for small companies. The Italian model makes use of a set of indicators concerning the exquisitely "financial" profile that is decidedly superior to Altman's model. Our model includes, in fact, the financial charges, the cash flow and the debt (Short-Term Liabilities) and credit (Short-Term Assets) situation. Theoretically, it could have expressed the potential risk of default much more strongly than Altman's index. This was not the case, however, given the results of our comparative analysis. How to explain this lower signalling capacity? A first answer can be found in the other indices included in the two protocols. The Italian model, unlike Altman's model, includes among its indices the level of sales (Revenues) but not of profitability (Net Income or Operational Income). As we know, profit is the primary source of self-financing, while the value of sales, even if it is growing, is no guarantee of profitability. Therefore, by excluding profit from the calculation of values intended to signal a situation of potential crisis, the Italian model leads to an underestimation of the risk of default. Profit measures, in fact, not only the company's ability to meet shareholders' expectations, but also and above all its ability to self-finance the business at zero cost. The other element that negatively affects the signalling capacity of this model, reducing it, lies in the way the evaluation protocol is applied: only when all 5 indices show a threshold value lower than those established by the sectoral table attached to the law, is the company considered at risk of default. These are companies in which the economic-financial situation is heavily compromised. It would be enough to reduce the number of indices to be considered in order to diagnose the crisis, in order to have an alert system with a greater signalling capacity. On the basis of this consideration it could be interesting to proceed with a new research, as mentioned above, aimed at selecting which of the indices contemplated by the Italian protocol are the least relevant to diagnose the state of crisis and exclude them from the list of indicators to be considered jointly.

Ultimately, the results of this research could therefore be useful to the legislator and the CNDCEC, to reconsider the index system adopted, or the way in which it is used. The current risk, in fact, in light of the results of our analysis, is that of generating an additional burden from the application of a protocol that has a reduced signalling capacity, thus thwarting the reasons that prompted the country to carry out this important reform.

\subsection{Opportunities and Limitations of this Research}

This work, clearly, has some limitations that derive from the data and the sample selection of the control group. It is obvious that, using different methodologies, it is plausible that the chosen companies can change and, for this reason, can slightly influence the results of the tests carried out. The choice of sectors was based on some decision criteria, and therefore, the work, as already stated, is not related to the entire Italian universe or to its macro sector, as the decision was to focus our attention on the ATECO codes that had the most problems in recent years. Furthermore, it should be noted that the CNDCEC methodology also refers to medium-sized enterprises (which have limits on total assets, revenue and the number of different workers). An all-inclusive 
analysis of this part of the reality could be the next step in future research. In addition, the AIDA database is constantly evolving; therefore, selecting a different sample (or repeating the same operation for a different time period) makes it possible to obtain results that deviate from those of this paper. Moreover, considering the regression model, it may be interesting to replicate the model for each sector, but to be able to repeat this step, it is important to have a larger sample to avoid any statistical discrepancies due to problems of representativeness. Finally, the efficiency and effectiveness of the model proposed by the CNDCEC in the macro-themes previously illustrated. The final result of this work may lead to an improvement that can not only guarantee a tool as simple and economical as possible to facilitate reform of the business crisis instrument but also to be able to guarantee the prevention of the bankruptcy due to timeliness and precision. As a future step, starting from this work, it might be interesting to develop a study that considers only the CNDCEC method to explore its limits to see whether its predictability can be improved by reducing, for example, the number of variables considered by the model or a different way of interpreting them.

\section{References}

Altman E. I. (1968). Financial ratios, discriminant analysis, and the prediction of corporate bankruptcy. Journal of Finance, 23(4), 589-609. https://doi.org/10.2307/2978933

Altman E. I., Hartzell, J., \& Peck, M. (1995). Emerging Markets Corporate Bonds: A Scoring System, Salomon Brothers Inc. New York. In Altman E.I., Hotchkiss E. (2006), Corporate Financial Distress and Bankruptcy. New York, NY: J. Wiley and Sons.

Altman, E. I. (1983). Corporate Financial Distress. New York. NY: Wiley Inter Science.

Altman, E. I. (2017). Altman Z-Score Models After 50 Years, Where We Are in the Credit Cycle and Outlook and the Italian Mini-bond Market. Credit Risk and Investment Strategy Seminar: Classis Capital.

Altman, E. I., \& Hotchkiss, E. (2006). Corporate Financial Distress and Bankruptcy (3rd ed.). Hoboken, NJ: J. Wiley and Sons.

Altman, E. I., \& Sabato, G. (2007). Modelling Credit Risk for SMEs: Evidence from the U.S. Market. Abacus. 43(3), 332-357. https://doi.org/10.1111/j.1467-6281.2007.00234.x

Altman, E. I., Danovi, A., \& Falini, A. (2013). La previsione dell'insolvenza: l'applicazione dello Z Score alle imprese in amministrazione straordinaria. Associazione Bancaria Italiana, n. 4-Aprile.

Altman, E. I., Sabato, G., \& Esentato, M. (2010). Il modello Z Score: un approccio per valutare le PMI italiane ed i Mini-bond sul mercato di credito dell'emittente. Retrieved from http://www.borsaitaliana.it/pro-link/partner/wiserfundingitalia/brochure.pdf

Altman, E. I., Sabato, G., \& Wilson, N. (2010). The value of non-financial information in small and medium-sized enterprise risk management. The Journal of Credit Risk, 6(2), 1-33. https://doi.org/10.21314/JCR.2010.110

Anderson T. W. (1958). An Introduction to Multivariate Statistical Analysis. New York, NY: Wiley and Son.

Arendt, H. (1977). Between past and future: Eight exercises in political thought. London: Penguin Books.

Argenti, J. (1983). Predicting corporate failure. London: Institute of Chartered Accountants in England and Wales.

Balcaen, S., \& Ooghe, H. (2004). 35 years of studies on business failure: an overview of the classical statistical methodologies and their related problems. Working Paper. Faculty of Economics and Business Administration, Ghent University.

Beaver W. H. (1966). Financial Ratios as Predictors of Failure. Journal of Accounting Research, 4(3), 71-111. https://doi.org/10.2307/2490171

Bimpong, P., Arhin, I., Hezkeal, K. N. T., Danso, E., Opoku, P., Benedict, A., \& Tettey, G. (2020). Assessing Predictive Power and Earnings Manipulations. Applied Study on Listed Consumer Goods and Service Companies in Ghana Using 3 Z-Score Models. Expert Journal of Finance, 8, 1-26.

Bottani, P., Cipriani, L., \& Serao, F. (2004). Il modello di analisi Z-Score applicato alle PMI. Amministrazione and Finanza, 19(1), 50-53.

Brooks, J. (1964). The fate of the Edsel and other business adventures. London: Gollancz.

Burns, T., \& Stalker, G. (1961). The management of innovation. London: Tavistock.

Cazdyn, E. (2007). Disaster, crisis, revolution. South Atlantic Quarterly, 106(4), 642-667. 
https://10.1215/00382876-2007-039

Celli, M. (2015). Can Z-Score Model Predict Listed Companies' Failures in Italy? An Empirical Test. International Journal of Business and Management, 10(3).

Chisholm-Burns, M. A. (2010), A crisis is a really terrible thing to waste. American Journal of Pharmaceutical Education, 74(2), 19-23 https://doi.org/10.5688/aj740219

Chowdhury, S., \& Lang, J. (1993). Crisis, decline, and turnaround: a test of competing hypotheses for short-term performance improvement in small firms. Journal of Small Business Management, 31(4), 8-17.

CNDCEC (Consiglio Nazionale Dottori Commercialisti). (2019). Crisi d'impresa. Gli indici dell'allerta. Ufficio Studi Consiglio Nazionale dei Dottori Commercialisti. Retrieved from https://commercialisti.it/documents/20182/1236821/codice+crisi_definizioni+indici+\%28ott+2019\%29.pdf/ 2072f95c-22a2-41e1-bd2f-7e7c7153ed84

Crutzen, N., \& Van Caillie, D. (2008), The Business failure process: An integrative model of the literature. Review of Business and Economics, 53(3), 288-316.

Danovi A., \& Quagli, A., (2008). Gestione della crisi aziendale e dei processi di risanamento: Prevenzione e diagnosi, terapie, casi aziendali. IPSOA, Wolters Kluwer.

Danovi, A., \& Acciaro, G. (2019a). Il Codice per la tutela autonoma allo status di imprenditore in crisi. Il Codice della crisi d'impresa e dell'insolvenza, 7,5-7.

Danovi, A., \& Acciaro, G. (2019b). Procedure di allerta e di composizione assistita della crisi. Milano: IlSole 24ore.

Deeson, A. F. (1972). Great company disaster. London: W. Foulsham Edition.

Faliva, M., \& Zoia, M. G. (2004). Econometric profiles of testing of statistical hypotheses: model specification tests. Statistica, 64(2), 257-269. https://doi.org/10.6092/issn.1973-2201/1263

Fitz Patrick, P. (1932). A comparison of ratios of successful industrial enterprises with those of failed firms. Certified Public Accountant, 2, 598-605.

Gao, J., \& Alas, R. (2010). The impact of crisis on enterprise life-cycle. Problems and Perspectives in Management, 8(2), 9-20.

Guanglu, X. (2021). Research on Financial Risk Early Warning of Listed Companies in Guangzhou Based on Z-Score Model. In 2021 2nd International Conference on E-Commerce and Internet Technology (ECIT) (pp. 239-244). IEEE.

Heath, R. (1998). Crisis management. London: Financial Times Professional.

Knüsel, L. (2005). On the accuracy of statistical distributions in Microsoft Excel 2003. Computational statistics and data analysis, 48(3), 445-449. https://doi.org/10.1016/j.csda.2004.02.008

Laitinen, E. K. (1991). Financial ratios and different failure processes. Journal of Business, Finance and Accounting, 18(5), 649-673. https://doi.org/10.1111/j.1468-5957.1991.tb00231.x

Mantovani, L. G., Olivieri, D., Patarnello, F., Banfi, F., Frizzo, V., Pitrelli, A., \& Scudellari, F. (2008). Mappatura dei database amministrativi e sanitari italiani: il Progetto AIDA (Atlante Italiano Database Amministrativi). Tendenze nuove, 8(4), 449-480. https://doi.org/10.1450/27519

Martire, F. (2013). La regressione logistica ei modelli log-lineari nella ricerca sociale. Milano: FrancoAngeli.

Mélard, G. (2014). On the accuracy of statistical procedures in Microsoft Excel 2010. Computational statistics, 29(5), 1095-1128. https://doi.org/10.1007/s00180-014-0482-5

Milašinović, M., Knežević, S., \& Mitrović, A. (2019). Bankruptcy forecasting of hotel companies in the Republic of Serbia using Altman's Z-score model. Hotel and Tourism Management, 7(2), 87-95.

Muñoz-Izquierdo, N., Laitinen, E. K., Camacho-Miñano, M. D. M., \& Pascual-Ezama, D. (2020). Does audit report information improve financial distress prediction over Altman's traditional Z-Score model? Journal of International Financial Management \& Accounting, 31(1), 65-97. https://doi.org.1111/jifm.12110

Niresh, J., \& Pratheepan, T. (2015). The application of Altman's z-score model in predicting bankruptcy: Evidence from the trading sector in Sri Lanka. International Journal of Business and Management, 10(12).

Normann, R., \& Ramirez, R. (1995). Lavorare insieme per produrre valore. Harvard Espansione, 2, 66-82. 
O'Connor, J. (1987). The meaning of crisis. New York, NY: Basil Blackwell.

Paruolo, P. (1999). Elementi di statistica. Bologna: Carocci.

Peters, T., \& Waterman, R. (1982). In search of excellence: Lesson from America's best-run companies. New York, NY: Harper Business Essentials.

Qiu, R. D. (2020). Refining Understanding of Corporate Failure through a Topological Data Analysis Mapping of Altman's Z-Score Model. Expert Systems with Applications, 156, 113475. https://doi.org/10.1016/j.eswa.2020.113475

Quagli, A. (2012). Piccole imprese, piccoli bilanci, piccoli ricercatori. Financial Reporting, 2, 5-9.

Ropega, J. (2011), The reasons and symptoms of Failures in SMEs'. International Advances in Economic Research, 17, 476-483. https://doi.org/10.1007/s11294-011-9316-1

Ross, J. E., \& Kami, M. J. (1973), Corporate management in crisis: Why the mighty fall. Upple Saddle River, New York, NY: Prentice-Hall.

Shafitra, N., Rizka, C., \& Noman, A. (2020). Prediction of Islamic Banking Bankruptcy in Indonesia: Comparative Study of Altman Z-Score and Springate Models. IKONOMIKA, 5(2), 231-248.

Slatter. S., Lovett, D., \& Barlow, L. (2008), Leading corporate turnaround. New York, NY: John Wiley and Sons.

Sloma, R. S. (2000), The turnaround manager's handbook. Washington DC: Beard Books.

Swaminathan, A. (1996). Environmental conditions at founding and organizational mortality: a trial-by- fire model. The Academy of Management Journal, 39(5), 1350-1377 https://doi.org/10.5465/257002

Van Dijk, B. (2021). AIDA database. Retrieved from https://aida.bvdinfo.com/version-2021415/home.serv?product=AidaNeo

Vella P. (2019). L'epocale introduzione degli strumenti di allerta nel sistema concorsuale italiano.

Zenga, M. (2014). Lezioni di statistica descrittiva: Seconda edizione. Torino: Giappichelli.

\section{Notes}

Note 1. Able to discriminate between failed and unsuccessful companies, Beaver's model is univariate: the discriminating variables (balance sheet indicators) are used one at a time.

Note 2. Information of the aida database are available here: AIDA database, https://aida.bvdinfo.com/version-2021415/home.serv?product=AidaNeo and Mantovani et al., 2008).

Note 3. see for further information about Hypothesis Testing: Zenga 2014; Faliva and Zoia 2004; Paruolo 1999.

Note 4. In the ATECO code the letters identify the economic macro-sector, while the numbers (from two to six figures) represent, with varying degrees of detail, the specific articulations and subcategories of the sectors themselves.

Note 5. The sample used by the CNDCEC to generate the predictive analysis model includes the financial statements of companies drawn up over the six years between 2010 and 2015. By applying the models that we intend to compare to the 2015 financial statements of the companies in our sample, verifying their signalling capacity in the light of the events that occurred in the period 2016-2018, we intend to give continuity and, at the same time, verify the validity of the analyses conducted by the CNDCEC.

\section{Copyrights}

Copyright for this article is retained by the author(s), with first publication rights granted to the journal.

This is an open-access article distributed under the terms and conditions of the Creative Commons Attribution license (http://creativecommons.org/licenses/by/4.0/). 